\title{
BMJ Open Risk of gastroschisis with maternal genitourinary infections: the US National birth defects prevention study 1997-2011
}

\author{
Marcia L Feldkamp, ${ }^{1}$ Kathryn E Arnold, ${ }^{2}$ Sergey Krikov, ${ }^{1}$ Jennita Reefhuis, ${ }^{2}$ \\ Lynn M Almli, ${ }^{2,3}$ Cynthia A Moore, ${ }^{2}$ Lorenzo D Botto ${ }^{1}$
}

To cite: Feldkamp ML, Arnold KE, Krikov S, et al. Risk of gastroschisis with maternal genitourinary infections: the US National birth defects prevention study 1997-2011. BMJ Open 2019;9:e026297. doi:10.1136/ bmjopen-2018-026297

- Prepublication history and additional material for this paper are available online. To view these files, please visit the journal online (http://dx.doi. org/10.1136/bmjopen-2018026297).

Received 5 September 2018 Revised 29 November 2018 Accepted 6 February 2019

Check for updates

(C) Author(s) (or their employer(s)) 2019. Re-use permitted under CC BY-NC. No commercial re-use. See rights and permissions. Published by BMJ.

${ }^{1}$ Division of Medical Genetics, Department of Pediatrics, University of Utah School of Medicine, Salt Lake City, Utah, USA

${ }^{2}$ National Center on Birth Defects and Developmental Disabilities, Centers for Disease Control and Prevention, Atlanta, Georgia, USA

${ }^{3}$ Carter Consulting, Inc, Atlanta, Georgia, USA

Correspondence to

Dr Marcia L Feldkamp;

marcia.feldkamp@hsc.utah.edu

\section{ABSTRACT}

Objective To assess the association between occurrence and timing of maternal self-reported genitourinary tract infection (urinary tract infections [UTIs] and/or sexually transmitted infection [STI]) and risk for gastroschisis in the offspring.

Design Population-based case-control study.

Setting National Birth Defects Prevention Study, a multisite study in the USA.

Participants Mothers of 1366 gastroschisis cases and 11238 healthy controls.

Main outcome measures Crude and adjusted ORs (aORs) with $95 \%$ Cls.

Results Genitourinary infections were frequent in case $(19.3 \%)$ and control women $(9.9 \%)$ during the periconceptional period (defined as 3 months prior to 3 months after conception). UTI and/or STI in the periconceptional period were associated with similarly increased risks for gastroschisis $(\mathrm{aOR} 1.5,95 \% \mathrm{Cl} 1.3$ to 1.8; aOR $1.6,95 \% \mathrm{Cl} 1.2$ to 2.3 , respectively). The risk was increased with a UTI before (aOR 2.5; 95\% Cl 1.4 to 4.5) or after (aOR 1.7; 95\% Cl 1.1 to 2.6) conception only among women $\geq 25$ years of age. The risk was highest among women $<20$ years of age with an STI before conception (aOR 3.6; $95 \% \mathrm{Cl} 1.5$ to 8.4 ) and in women $\geq 25$ years of age, the risk was similar for before (aOR $2.9 ; 95 \% \mathrm{Cl} 1.0$ to 8.5$)$ and after (aOR $2.8 ; 95 \% \mathrm{Cl} 1.3$ to 6.1 ) conception. A specific STI pathogen was reported in $89.3 \%$ (50/56) of cases and 84.3\% (162/191) of controls with Chlamydia trachomatis the most common (25/50 cases, 50\%; 58/162 controls, $36 \%$ ) and highest among women $<20$ years of age ( $16 / 25$ cases, $64 \%$; $22 / 33$ controls, $67 \%$ ).

Conclusions UTI and/or STI were associated with an increased risk for gastroschisis, with the strength of the association varying by maternal age and timing of infection.

\section{INTRODUCTION}

Gastroschisis is a severe abdominal defect in which the midgut prolapses outside the abdominal cavity, usually on the right, adjacent to the umbilical cord. The mechanism underlying this birth defect is not understood. Rittler et $a l^{\mathrm{l}}$ proposed a failure in the

\section{Strengths and limitations of this study}

- This is a case-control study with case infants identified from population-based surveillance systems and control infants randomly selected from the same population among the 10 centres throughout the USA.

- Mothers of cases and controls were interviewed by trained interviewers using a computerised-access telephone interview between 6 weeks and 24 months after the estimated date of delivery. Recall bias may impact the findings of this study.

- The gastroschisis case group was clinically well defined and reviewed by one geneticist involved in the study.

- A large proportion of sexually transmitted infections are asymptomatic and the use of maternal self-report for infection status may likely misclassify many women as unexposed.

normal attachment between the umbilical cord and umbilical ring perhaps due to a decrease in cell deposition that then weakens the cord attachment on one side. If this is the mechanism that results in gastroschisis, the critical timing of an exposure may involve several months: before or after conception, or, before, during or after the merging of the body stalk and omphalomesenteric stalk (21-35 days postconception). ${ }^{2}$ The prevalence of gastroschisis in recent decades shows a remarkable and worrying increasing trend in the $\mathrm{USA}^{3-6}$ and elsewhere, ${ }^{78}$ suggesting a role of an environmental factor yet unknown. Most infants with gastroschisis (approximately $80 \%$ in several studies) ${ }^{679}$ are born to women under 25 years of age, and rates are highest among infants born to the youngest mothers $(<20$ years of age), for reasons that are unclear. These two epidemiological traits could be tied together by environmental risk factors that are increasing and also either more common or more harmful in younger 
women. One such environmental factor under investigation consists of genitourinary tract infections (GUIs), which include urinary tract infections (UTIs) and/or sexually transmitted infections (STIs). Both UTIs and STIs occur more frequently among young sexually active women. ${ }^{10}{ }^{11}$ In addition, young women appear comparatively more susceptible to STI, particularly Chlamydia trachomatis and gonorrhoea, due to cervical ectropion. ${ }^{12} 13$

Several studies have documented an association between gastroschisis and either self-reported GUI ${ }^{14-19}$ or antiviral medications used to treat an STI. ${ }^{20}$ The methods in these studies, especially how the infections and the timing were documented or diagnosed, vary considerably. A recent study ${ }^{21}$ noted a fourfold increased risk for gastroschisis among women with seropositivity during pregnancy to anti-C. trachomatis $\operatorname{IgG}_{3}$, suggesting a role for recent STI due to C. trachomatis. However, in a Finnish cohort, no association was observed between C. trachomatis-specific IgG and gastroschisis, ${ }^{22}$ though a twofold increased risk was observed with presence of antibodies to herpes simplex virus type 2 (HSV-2) during early pregnancy. ${ }^{23}$

This study aimed at expanding the size and scope of the original analysis (1997-2003 births) from the National Birth Defects Prevention Study (NBDPS) ${ }^{15}$ to better assess the relationship between self-reported periconceptional GUIs and gastroschisis in terms of infection type (UTI, STI), timing of infection and reported pathogen.

\section{MATERIAL AND METHODS \\ Study design}

The NBDPS is a multisite, population-based case-control study based on data from 10 centres (Arkansas, California, Georgia, Iowa, Massachusetts, New Jersey, New York, North Carolina, Texas and Utah), designed to investigate the environmental and genetic risk factors for non-syndromic birth defects. ${ }^{24}$

Case infants with eligible birth defects were identified from the centres' population-based birth defects surveillance systems. NBDPS cases included any live-born infant or fetus (ie, stillborn or a result of a pregnancy termination) with an estimated date of delivery (EDD) from October 1997 to December 2011. Controls were live-born infants without major birth defects randomly selected from either birth certificates or hospitals from the same birth population. Women were asked to participate in a computer-assisted telephone interview in either English or Spanish between 6 weeks and 2 years after the EDD. The interview included questions on demographics, medication use, illnesses, and occupational, lifestyle and other exposures from 3 months before through the end of pregnancy.

\section{Case classification}

Clinical data on each birth defect case were reviewed for eligibility by each centre's clinician before the interview occurred. Clinical information on infants with gastroschisis was reviewed by one investigator (CAM) and classified as having isolated or multiple defects. ${ }^{25} \mathrm{We}$ excluded any gastroschisis case that was suggestive of or classified as a limb-body wall complex or amniotic band sequence.

Overall participation rates were 65\% (1506 interviewed/2332 eligible) for case and 64\% (11 329 interviewed/18 614 eligible) for control mothers. The median time from EDD to interview was $9.5( \pm 6.3)$ months for case women and $8.6( \pm 6.5)$ months for control women. The study group included 1506 cases and 11829 controls. We then excluded 62 cases and 223 controls who did not complete the interview; 56 cases because of a limb-body wall complex or amniotic band sequence diagnosis; and 22 cases and 368 controls with pregestational diabetes. Thus, the final study group comprised 1366 cases and 11238 controls. Among all NBDPS control women that did not participate, maternal, paternal and infant characteristics were similar to the underlying population of randomly selected controls. ${ }^{26}$

\section{Exposure assessment}

Three questions captured information on UTI and/or STI: 'Did you have any of the following illnesses': (1) 'a kidney, bladder or UTI?'; (2) 'pelvic inflammatory disease or PID?' and (3) 'Did you have any other diseases or illnesses that we have not already talked about such as... sexually transmitted diseases?'. Women were considered exposed if they reported either a UTI or STI at any time from 3 months before conception through the end of the first trimester of pregnancy (B3-P3). Any woman reporting PID was considered to have an STI, since two sexually transmitted pathogens, C. trachomatis or Neisseria gonorrhoeae, are among the major causes of PID. ${ }^{27}$ Blinded to case or control status, two investigators (MLF and KEA) reviewed all free-text responses to the question regarding 'other diseases or illnesses' to code any UTI or STI, and to code the pathogen if reported by the woman. Reviewers' discrepancies $(n=51)$ were addressed by a blinded investigator (LDB) to make the final determination for the freetext responses.

We created three main exposure groups: any GUI (UTI and/or STI), UTI and STI. Two case and four control mothers reported both a UTI and STI during B3-P3. The unexposed group included women that did not report a UTI or STI during B3-P3. We evaluated infections reported prior to conception (B3-B1), after conception (P1-P3) and the entire period (B3-P3). Any woman reporting a UTI and/or STI in the second and/or third trimester was considered unexposed for this study. Women who were not able to report the actual timing of their infection were excluded.

\section{Statistical analysis}

For all analyses, we used the eligible cases and controls from the entire period, 1997-2011. We assessed the distribution of maternal characteristics and infection status by case-control women with Pearson's $\mathrm{X}^{2}$ test. We 
used logistic regression to investigate the relationship between gastroschisis and GUIs. Crude OR (cOR) and adjusted ORs (aORs) with 95\% CIs were calculated for any GUI, by subtype (UTI, STI), timing of infection, and if reported, specific pathogens and the risk for gastroschisis. We used the Breslow-Day test for homogeneity to assess ORs for the two time periods (1997-2003, 20042011) for each infection type. Based on our previous work, ${ }^{15}$ ORs were adjusted for the following a priori set of covariates: maternal age (continuous), race/ethnicity (non-Hispanic white (reference), Hispanic, other), cigarette smoking (yes, no (reference)), prepregnancy body mass index (BMI: weight in kilograms/height in metres ${ }^{2}$ ) (underweight, normal (reference), overweight, obese) and gestational diabetes (yes, no (reference)). We used a stratified analysis to assess the risk of gastroschisis within each maternal age category and evaluated whether maternal age, cigarette smoking and infection status are independent risk factors or interact to increase the risk of gastroschisis. Additive effects of infection and maternal age on gastroschisis were evaluated by calculating the relative excess risk due to interaction (RERI) ${ }^{28-30}$ Under the null hypothesis of no interaction, we would expect a RERI of zero, attributable proportion of zero and a synergy index of one in the additive model.$^{28}$ All analyses were conducted using SAS V.9.1 (SAS).

\section{Patient and public involvement}

Two federal mandates were responsible for the creation of the Centers for Birth Defects Research at Centers for Disease Control and Prevention ${ }^{24}$ : the Congressional mandate in 1996 and the Birth Defects Prevention Act in 1998. After these mandates, the NBDPS was designed and conducted by participating centres around the country. Mothers of infants with and without a birth defect were not involved in the study design or questionnaire development, however, participants were asked: 'Is there anything, including some of the factors we've talked about that you think might cause birth defects?' and the responses were considered when making changes to the questionnaire. The NBDPS collaborators have shared results of some analyses via an NBDPS newsletter with participants, available on the NBDPS website (http://nbdps.org).

\section{RESULTS}

\section{Prevalence of infection and overall risk}

Case and control women differed with respect to age, race/ethnicity, education, smoking, BMI and gestational diabetes (table 1). In all the strata except for underweight women (BMI $<18.5 \mathrm{~kg} \mathrm{~m}^{2}$ ) case women reported UTI and/or STI more frequently than control women. We excluded $28(2.0 \%)$ case and $129(1.1 \%)$ control women from further analyses as they did not report a specific month of their GUI (table 1). Mothers of infants with gastroschisis reported a UTI, STI or any GUI 3 months before (B3) to 3 months after (P3) conception more frequently compared with mothers of infants without birth defects (figure 1). Overall, gastroschisis was associated with an increased risk for women reporting a GUI (aOR 1.6, 95\% CI 1.3 to 1.9) during the periconceptional period and this was similar when stratified by infection type (UTI: aOR $1.5,95 \%$ CI 1.3 to 1.8 ; STI: aOR 1.6, $95 \%$ CI 1.2 to 2.3) (figure 2; data in online supplementary table 1). cOR and aOR with 95\% CIs were not statistically significantly different comparing the period (1997-2003) covered by our earlier paper ${ }^{15}$ to the 2004-2011 time period for each infection type (UTI, STI or GUI) (test of homogeneity for each infection and time period comparison ranging between $\mathrm{p}=0.55$ and 0.98 ) (online supplementary table 2).

\section{Risk by infection, age, smoking}

When the analysis was stratified by GUI, smoking and maternal age, the highest odds were observed in women who were concurrently young, smokers and with a reported GUI (table 2). The estimated relative risk in this group (young women who reported both smoking and a GUI) was 25 times that of the lowest risk group (women who were non-smokers, reported no history of a GUI and were $\geq 25$ years of age). This pattern was similar when the timing of the reported GUI was restricted to before (B3B1) or after (P1P3) conception (data not shown).

\section{Risk by timing of infection}

Gastroschisis was associated with an increased risk for women reporting either a UTI (aOR 1.8, 95\% CI 1.3 to 2.4) or STI (aOR 2.1, 95\% CI 1.3 to 3.4) prior to conception (figure 2; data in online supplementary table 1). The strongest association (aOR 3.6, 95\% CI 1.5 to 8.4) was observed among women with an STI prior to conception who were $<20$ years of age. By comparison, an infection after conception was associated with an aOR of 1.5 (95\% CI 0.8 to 2.7) (figure 2; data in online supplementary table 1 ). Women $\geq 25$ years of age reporting a UTI were at an increased risk for having an infant with gastroschisis if the infection occurred prior to (aOR 2.5, 95\% CI 1.4 to 4.5 ) or after conception (aOR 1.7, 95\% CI 1.1 to 2.6) and risk was highest among women reporting an STI prior to (aOR 2.9, 95\% CI 1.0 to 8.5) or after conception (aOR 2.8, 95\% CI 1.3 to 6.1 ) (figure 2; online supplementary table 1).

\section{Interaction between maternal age and infection}

Based on aORs, we observed a positive synergistic interaction on the additive scale between young maternal age and infection for risk of gastroschisis (online supplementary table 3 ). Co-occurrence of maternal age between 20-24 years and UTI increases gastroschisis risk more than the sum of each of these risk factors alone. While the RERI for maternal age $<20$ years and STI was suggestive of a positive interaction, the estimate was imprecise (CIs included zero).

\section{Risk by type of STI pathogen}

Among those women reporting an STI, 89\% (50/56) of the case women and $85 \%(162 / 191)$ of the control 
Table 1 Maternal characteristics and infection status among gastroschisis cases and controls, National Birth Defects Prevention Study, 1997-2011

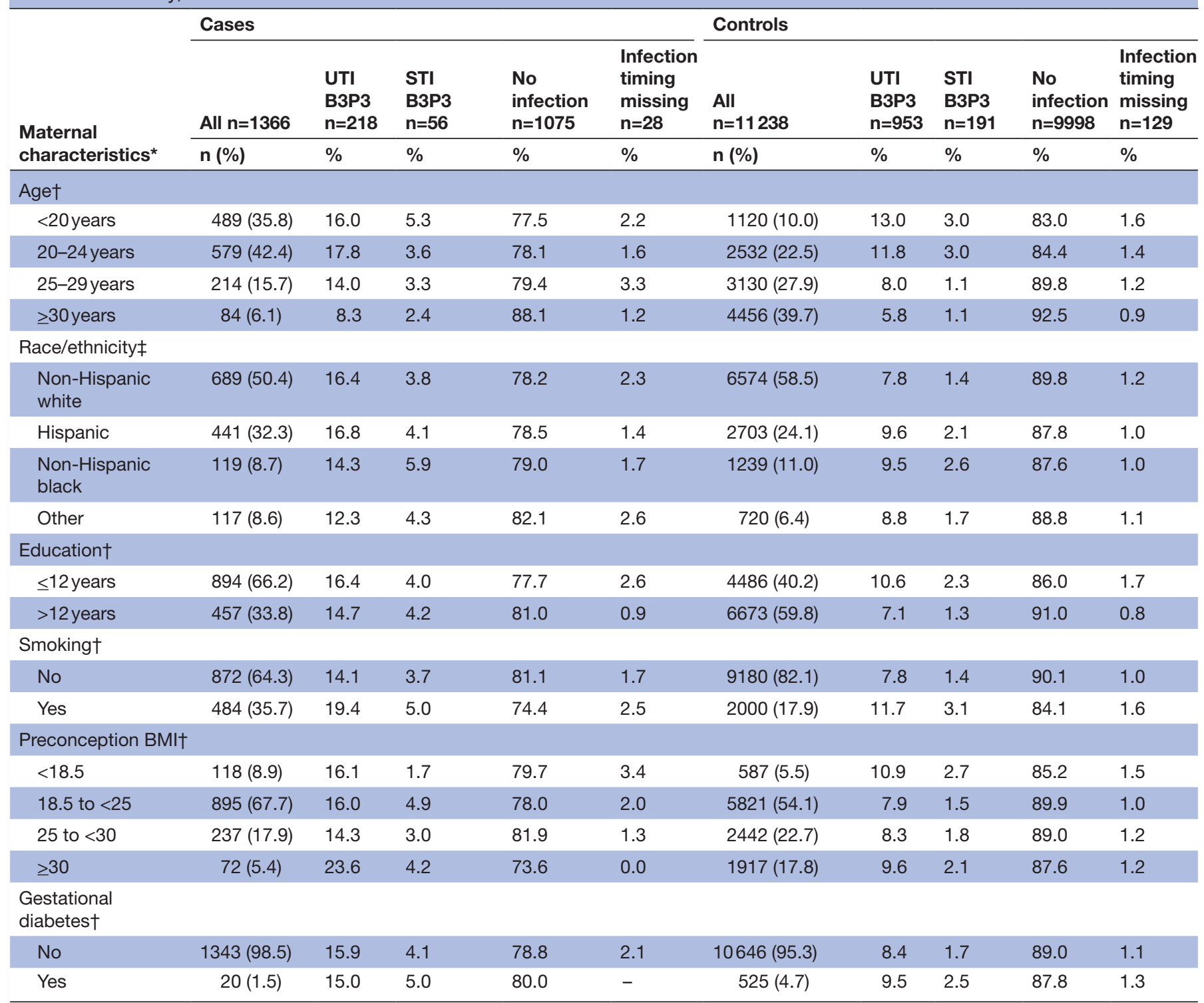

Counts and per cents for each of the infection categories can add up to more than $100 \%$ since women could report both a UTI and an STI. B3P3: 3 months before (B3) to 3 months after (P3) conception.

*Missing data for each characteristic are not included.

$+\mathrm{P}<0.0001$.

$\ddagger P=0.0003$ Comparing distribution between cases and controls ( $p$ value calculated using $\chi^{2}$, excluding missing data).

$\mathrm{BMI}$, body mass index $\mathrm{kg} / \mathrm{m}^{2}$; STI, sexually transmitted infection; UTI, urinary tract infection.

women were able to report a specific pathogen (one case and nine controls reported two pathogens each): $C$. trachomatis was the most commonly reported pathogen (25/50 cases, $50 \%$; 58/162 controls, $36 \%)$. C. trachomatis was reported more often in women less than 20 years of age (cases $16 / 25,64 \%$; controls $22 / 33,67 \%$ ) than among women aged 20-24 years (cases 7/21, 30\%; controls $30 / 77,39 \%$ ) and women 25 years and older (cases 2/9, 22\%; controls 6/81, 7\%). Both C. trachomatis (cOR 3.6, 95\% CI 2.2 to 5.8 ) and gonorrhoea (cOR 3.3, 95\% CI 1.0 to 10.5 ) infections were associated with gastroschisis (figure 3 ).

\section{DISCUSSION}

Genitourinary infections shortly before and in the first trimester of pregnancy were associated in this study with an approximately twofold increase in risk for gastroschisis, confirming and supporting earlier findings. ${ }^{15} \mathrm{~A}$ more detailed analysis, however, showed that this overall estimate hides a much more varied, and wider risk profile. For example (table 2), the risk for gastroschisis in a pregnancy of woman who is $<20$ years of age, smokes and has a GUI in early pregnancy is 25 times that of a woman who does not have these characteristics (ie, is $\geq 25$ years of age, does not smoke and does not have a GUI). 


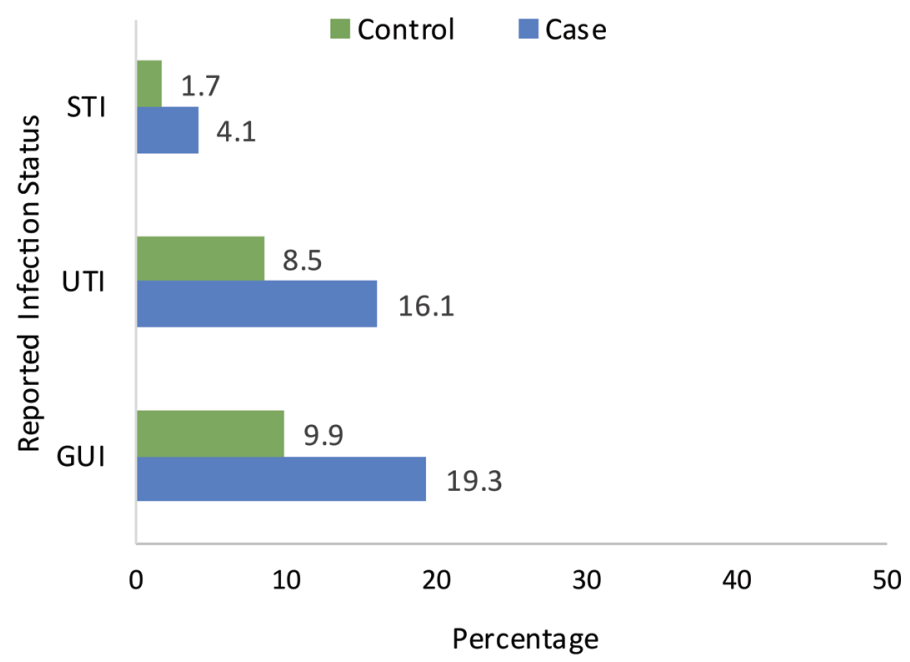

Figure 1 Proportion of case and control women reporting a sexually transmitted infection (STI), urinary tract infection (UTI) or any genitourinary tract infection (GUI) anytime during the 3 months before (B3) and after (P3) conception, National Birth Defects Prevention Study, 1997-2011.

STI and UTI have similar associations with gastroschisis. Among women reporting STI, C. trachomatis was the most frequently reported pathogen $(50 \%(\mathrm{n}=25 / 50)$ of case mothers and $36 \%(n=58 / 162)$ of control mothers).

These findings suggest that GUIs are a risk factor for gastroschisis. However, one important issue is whether GUIs can also explain the unusual occurrence patterns of gastroschisis, in particular, the increasing time trend overall and the remarkably high rate among the offspring of the youngest mothers. STIs and UTIs are common among sexually active young women. In the USA, women 15-24 years of age account for 50\% of all new STIs (http://www.cdc.gov/std/stats). In 2015, rates of STI were highest among women 19 and 20 years of age. ${ }^{31}$ Chlamydial infection rates continued to increase between 2007 and 2012, with the highest rate reported among the youngest women (14-19 years). ${ }^{31}$ The observation that an STI prior to conception (B3B1) is a comparatively stronger

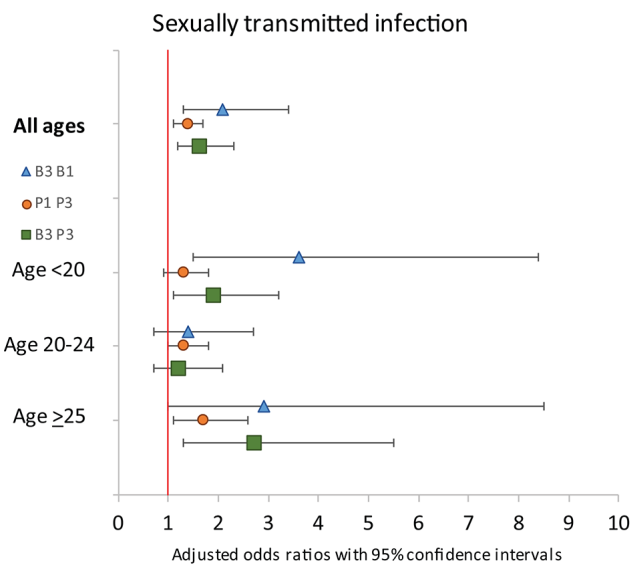

risk factor among women $<20$ years of age (figure 2 ) is intriguing for several reasons. First, young women are at an increased risk for acquiring an STI in part because of their cervical histology. After the onset of menarche, the cervical epithelium everts and exposes the immature columnar epithelial cells (cervical ectropion or ectopy). ${ }^{12}$ Cervical ectropion is common in adolescents, pregnant women and women taking oestrogen-containing contraceptives. ${ }^{32}$ The preferential attachment sites of C. trachomatis and $N$. gonorrhoeae are the columnar epithelium and transitional epithelial cells. ${ }^{33}$ With increasing age, these columnar cells increasingly convert to squamous epithelial cells that line the cervix, which are less susceptible to these two pathogens, ${ }^{12}$ but if this barrier is breached, the pathogen can access cells in the basal layer. ${ }^{34}$ Second, young women may engage in risky behaviours including multiple or changing sex partners, ${ }^{21} 35$ alcohol use ${ }^{36}$ and substance abuse ${ }^{4738}$ that increase the likelihood

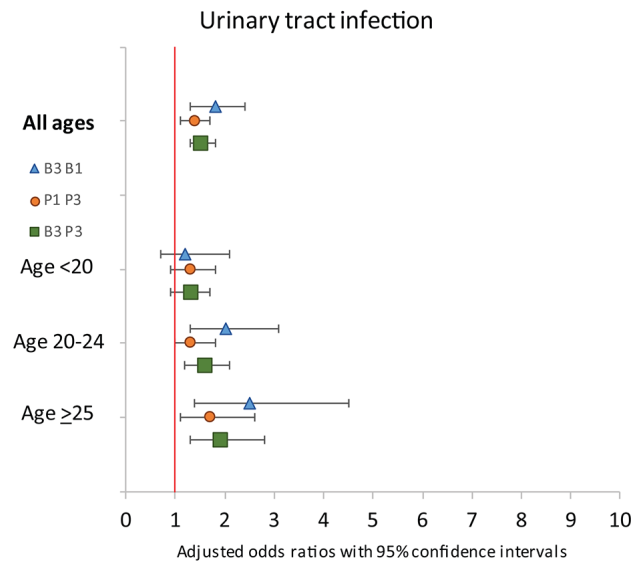

Figure 2 Adjusted ORs and 95\% Cls stratified by infection type, maternal age and time period of infection (B3B1, P1P3, B3P3) National Birth Defects Prevention Study, 1997-2011. B3B1, 3 months before conception; B3P3, 3 months before (B3) to 3 months after (P3) conception; P1P3, first 3 months after conception. 
Table 2 Crude ORs for gastroschisis by maternal age ( $<20$ or $20-24$ compared with $\geq 25$ years of age), smoking and genitourinary infection status, alone and in combination, National Birth Defects Prevention Study, 1997-2011

\begin{tabular}{llllccl}
\hline Age (years) & Smoking & GUI B3P3 & Case $(\mathbf{n})$ & Control $\mathbf{( n )}$ & Crude OR & $\mathbf{9 5 \%} \mathbf{C l}$ \\
\hline$\geq 25$ & - & - & 166 & 6012 & 1.0 & \\
$\geq 25$ & - & + & 22 & 470 & 1.7 & 1.1 to 2.7 \\
$\geq 25$ & + & - & 76 & 893 & 3.1 & 2.3 to 4.1 \\
$\geq 25$ & + & + & 24 & 106 & 8.2 & 5.1 to 13.1 \\
$20-24$ & - & - & 288 & 1573 & 6.6 & 5.4 to 8.1 \\
$20-24$ & - & + & 67 & 231 & 10.5 & 7.7 to 14.4 \\
$20-24$ & + & - & 162 & 554 & 10.6 & 8.4 to 13.4 \\
$20-24$ & + & + & 50 & 126 & 14.4 & 10.0 to 20.6 \\
$<20$ & - & - & 253 & 684 & 13.4 & 10.9 to 16.6 \\
$<20$ & - & + & 61 & 116 & 19.1 & 13.5 to 26.9 \\
$<20$ & + & - & 38 & 54 & 25.5 & 14.4 to 24.6 \\
$<20$ & + & + & & & & 16.4 to 39.7 \\
\hline
\end{tabular}

B3P3: 3 months before (B3) to 3 months after (P3) conception.

GUI, genitourinary tract infection.

of acquiring an STI or UTI. ${ }^{21}$ Recent sexual activity, frequency of sexual activity and number of sexual partners also pose an increased risk of a $\mathrm{UTI}^{39}$ and these infections in young women may be an indication of their sexual debut. ${ }^{40}$ Infections caused by C. trachomatis or $N$. gonorrhoea may also mimic symptoms of a UTI (pain or burning sensation during urination). ${ }^{41}$ Common pathogens that cause a UTI include Escherichia coll $^{42}$ and Klebsiella ${ }^{43}$ but without a urine culture, the specific pathogen cannot be identified based on symptoms alone. UTI and STI have overlapping symptomatology and a diagnosis of a UTI without culture will sometimes miss an STI, particularly those infections caused by C. trachomatis. ${ }^{445}$ Third, C. trachomatis is a pathogen that is known to elicit inflammation $^{33} 46$ as the infectious particle (elementary body) replicates and spreads by infecting columnar epithelial cells, locally causing tubal factor infertility ${ }^{47}$ and systemically in the synovial fluid among those with reactive arthritis. ${ }^{48-51}$
How a GUI might cause gastroschisis during pregnancy remains an open question. We postulate that the mechanism could be related to the specific pathogens or alternatively to the inflammatory response generated by the pathogen that may result in cell destruction at the attachment site of the umbilical cord and umbilical ring. If inflammation is the true risk factor and an STI or UTI occurs immediately prior to pregnancy or at the time of conception this may explain the elevated risk we observed in the 3-month period prior to conception (B3-B1 in figure 2). Asymptomatic infections can cause inflammation, unbeknownst to the individual, but how long the inflammatory process can continue is not known.

How an individual responds to any pathogen is regulated by the genetically controlled innate and adaptive immune system, ${ }^{52}$ the magnitude of which may differ between case and control women. ${ }^{21}$ This difference in the genetically regulated response to an antigen may explain why not all STIs or UTIs during the critical time period

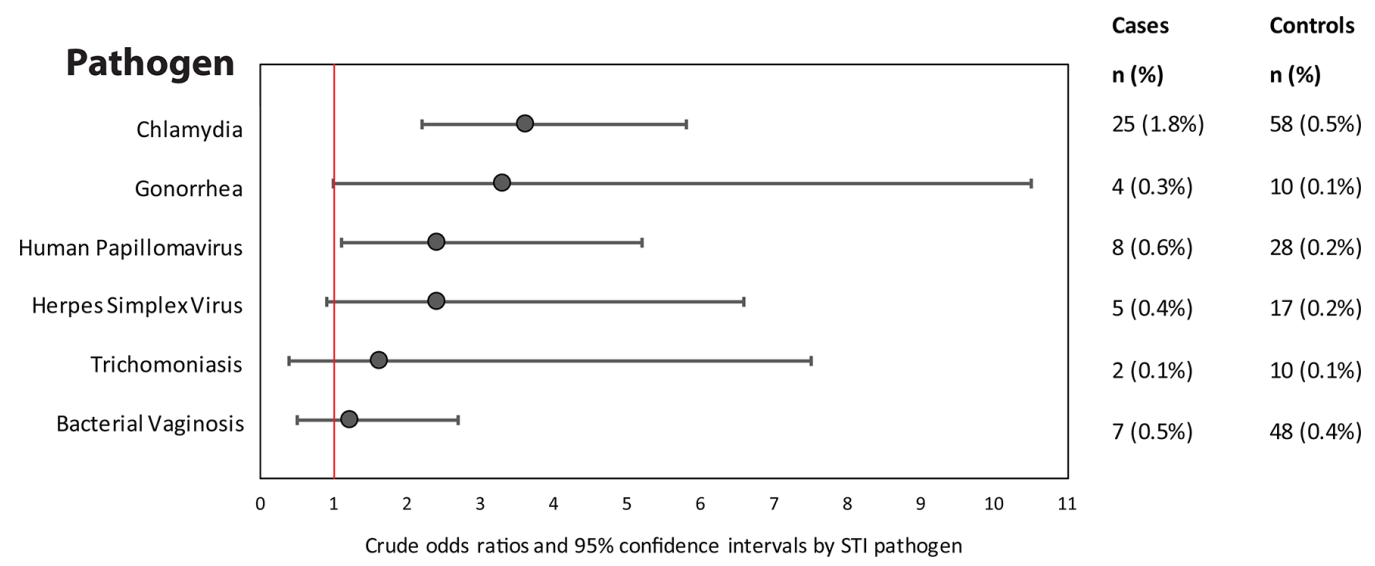

Figure 3 Crude ORs and 95\% Cls stratified by sexually transmitted infection (STI) pathogen, National Birth Defects Prevention Study, 1997-2011. 
of embryonic development result in the development of gastroschisis. For C. trachomatis, the immunogenetic response to the pathogen determines whether the infection will be cleared with or without a serious proinflammatory response. ${ }^{53-55}$

Investigating bacterial, viral and other causes of STI is difficult because they are often asymptomatic and testing for all possible pathogens is expensive. C. trachomatis and $N$. gonorrhoeae are challenging bacterial STIs to investigate because asymptomatic infections are common in women (C. trachomatis 75\%-90\%; gonorrhoea $50 \%$ ) and may lead to systemic infection or inflammation. ${ }^{334}$ Whereas N. gonorrhoeae rates in the USA have either remained stable or declined through 2014 and since have increased slightly each year, $C$. trachomatis rates have increased during the same time period and it is the most prevalent bacterial STI. ${ }^{27}$ Specifically, among women less than 25 years of age, C. trachomatis is the most commonly reported communicable disease. ${ }^{56}$ Unfortunately, the common viral pathogens that cause STI (human papillomavirus, HSV-2) and bacterial vaginosis are not reportable conditions, making it more challenging to assess infection rates. ${ }^{31}$ Recent data measuring seroprevalence suggest both viral pathogens have declined slightly. Seroprevalence of HSV-2 in 14-49 years of age decreased from $21.2 \%$ (1988-1994) to $15.5 \%$ (2007-2010). ${ }^{57}$ Seroprevalence of HPV also decreased from the prevaccine era (2003-2006) to the postvaccine era (2009-2012) in females $14-19$ and $20-24$ years of age. ${ }^{58}$

\section{Limitations and strengths of this study are important to consider}

The most serious limitation is the use of maternal self-report to assess infection status. Because of the large proportion of STIs that are asymptomatic and pathogens that are capable of mimicking a UTI, the true risk for gastroschisis due to a GUI is not known. In this study, only a small proportion of women reported an infection, particularly an STI, and it is quite low compared with evidence that one in four teens will contract an STI ${ }^{59}$ and by the age of 25 years, one in two sexually active people will contract an STI. ${ }^{60} \mathrm{~A}$ recent study reported a $31 \%$ seroprevalence for $C$. trachomatis among women participating in a community study for a herpes vaccine trial. ${ }^{61}$ Though this and previous studies based on self-reported infections provide initial clues about the association with gastroschisis, under-reporting of asymptomatic infections are a major concern. These associations require more robust detection methods that use sensitive biomarkers (such as pathogen-specific immunoglobulin tests) to determine infection and pathogen status immediately prior to pregnancy or during the first trimester. Common bacterial pathogens (such as $C$. trachomatis and $N$. gonorrhoeae) and recently discovered pathogens (such as genital mycoplasmas (Mycoplasma genitalium and Mycoplasma hominis) and ureaplasmas (Ureaplasma urealyticum and Ureaplasma parvum)) are best evaluated with studies done during pregnancy to assess exposure using urine, blood and vaginal swabs. Other limitations include the time from EDD to interview which may affect recall of infection, cigarette smoking or preconception weight used to calculate BMI. Recall bias of a GUI is a concern and may have impacted our study's findings. Misdiagnosis of the GUI and asymptomatic infection are also a concern. An ideal approach would be to combine prenatally collected serum biomarkers with review of the prenatal medical records. ${ }^{21}$ However, the potential for reporting bias of cigarette smoking in the NBDPS was assessed using two different methods, which did not find any evidence of differential recall. ${ }^{6263}$ Another study found maternal smoking was actually more often reported in the NBDPS interview compared with the medical record or birth certificate data. ${ }^{64}$ Preconception weight is known to be under-reported by $1-2 \mathrm{~kg}$ and is most pronounced in the obese group, ${ }^{65}$ but would not be expected to differ by case-control status. This misclassification would likely shift effect estimates towards the null, thus underestimating the true risk. To minimise misclassification bias, the NBDPS used trained interviewers, blinded to case-control status and used a computerised and scripted questionnaire to capture exposure information. Confounding by indication (antibiotic use) was not examined as a recent analysis ${ }^{66}$ assessed the risk of birth defects associated with the use of different antibiotics and gastroschisis was not associated with these medications. Finally, residual (unmeasured) confounding may have influenced the study's findings. Strengths of this study include the population-based case and randomly selected control group, the clinically reviewed and well-defined gastroschisis case group, and the systematic collection of maternal information from case and control women based on 10 centres throughout the USA.

\section{CONCLUSIONS}

Our findings support an association between gastroschisis and GUIs in early pregnancy and in the 3 months before conception. ${ }^{14-19}$ Young women $(<20$ years of age), particularly if also smokers, are at greatest risk. Because of its frequency, C. trachomatis may be the pathogen associated with most GUI-associated cases of gastroschisis. Finally, these estimates could represent a lower boundary of the true risk, as they are based on maternal self-reports that would miss asymptomatic infections, particularly common for STIs. ${ }^{27}{ }^{61}$ Strategies should be explored to address and reduce these maternal risk factors, especially in the population of young women. In order to clarify the role of GUIs before and during early pregnancy and risk of gastroschisis, the collection of biomarkers (ie, blood, urine and vaginal swabs) to assess pathogens during early pregnancy, for example, at the time of the diagnostic ultrasound at 18-20 weeks gestation, would be useful. 
We also encourage other investigators to evaluate gastroschisis and STIs (particularly, C. trachomatis) to see if our observation can be confirmed in countries, or regions, where there may or may not be an increase in the prevalence of gastroschisis.

Acknowledgements We especially thank those women participating in the National Birth Defect Prevention Study, whose time and information were critical for this study. We also would like to thank all the collaborators of the Centers for Birth Defects Research and Prevention in Arkansas, California, Georgia, lowa, Massachusetts, New Jersey, New York, North Carolina, Texas and Utah for their data contributions.

Contributors MLF designed the study question, led the analysis and development and writing of the manuscript. Phenotype review and classification conducted by CAM. Coding the free text data from the questionnaire was completed by MLF and KEA. Statistical analysis and data replication conducted by SK and LMA. MLF, KEA, SK, LMA, JR, CAM and LDB were all involved in data interpretation and assisted with the writing of the manuscript and the critical review of the manuscript.

Funding This study was supported by Cooperative Agreements No. U50/ CCU822097 and U01-DD000490 from the Centers for Disease Control and Prevention.

Disclaimer The findings and conclusions in this report are those of the authors and do not necessarily represent the official position of the Centers for Disease Control and Prevention.

Competing interests None declared.

Patient consent for publication Not required.

Ethics approval Institutional review boards at the Centers for Disease Control and Prevention (CDC) and at each participating centre approved the study.

Provenance and peer review Not commissioned; externally peer reviewed.

Data sharing statement № additional data are available.

Open access This is an open access article distributed in accordance with the Creative Commons Attribution Non Commercial (CC BY-NC 4.0) license, which permits others to distribute, remix, adapt, build upon this work non-commercially, and license their derivative works on different terms, provided the original work is properly cited, appropriate credit is given, any changes made indicated, and the use is non-commercial. See: http://creativecommons.org/licenses/by-nc/4.0/.

\section{REFERENCES}

1. Rittler M, Vauthay L, Mazzitelli N. Gastroschisis is a defect of the umbilical ring: evidence from morphological evaluation of stillborn fetuses. Birth Defects Res A Clin Mol Teratol 2013;97:198-209.

2. Feldkamp ML, Carey JC, Sadler TW. Development of gastroschisis: review of hypotheses, a novel hypothesis, and implications for research. Am J Med Genet A 2007;143A:639-52.

3. Kirby RS, Marshall J, Tanner JP, et al. Prevalence and correlates of gastroschisis in 15 states, 1995 to 2005. Obstet Gynecol 2013;122:275-81.

4. Vo LU, Langlois $\mathrm{PH}$. Time trends in prevalence of gastroschisis in Texas, 1999 to 2011: Subgroup analyses by maternal and infant characteristics. Birth Defects Res A Clin Mol Teratol 2015;103:928-40.

5. Yang W, Carmichael SL, Shaw GM. Folic acid fortification and prevalences of neural tube defects, orofacial clefts, and gastroschisis in California, 1989 to 2010. Birth Defects Res A Clin Mol Teratol 2016;106:1032-41.

6. Jones AM, Isenburg J, Salemi JL, et al. Increasing prevalence of gastroschisis-14 states, 1995-2012. MMWR Morb Mortal Wkly Rep 2016;65:23-6.

7. Nazer Herrera J, Karachon Essedin L, Cifuentes Ovalle L, et al. [Gastroschisis: a pandemic with increasing rates? ECLAMC experience in Chile 1982-2015]. Rev Chil Pediatr 2016;87:380-6.

8. Bugge M, Drachmann G, Kern P, et al. Abdominal Wall Defects in Greenland 1989-2015. Birth Defects Res 2017;109:836-42.

9. Feldkamp ML, Botto LD, Byrne JLB, et al. Clinical presentation and survival in a population-based cohort of infants with gastroschisis in Utah, 1997-2011. Am J Med Genet A 2016;170:306-15.

10. Huppert JS, Biro F, Lan D, et al. Urinary symptoms in adolescent females: STI or UTI? J Adolesc Health 2007;40:418-24.
11. Wangu Z, Burstein GR. Adolescent sexuality: updates to the sexually transmitted infection guidelines. Pediatr Clin North Am 2017;64:389-411.

12. Matiluko AF. Cervical ectropion. Part 1: appraisal of a common clinical finding. Trends Urol Gynaecol Sex Health 2009.

13. Feldkamp ML, Ward DM, Pysher TJ, et al. Chlamydia trachomatis is responsible for lipid vacuolation in the amniotic epithelium of fetal gastroschisis. Birth Defects Res 2017;109:1003-10.

14. Draper ES, Rankin J, Tonks AM, et al. Recreational drug use: a major risk factor for gastroschisis? Am J Epidemiol 2008;167:485-91.

15. Feldkamp ML, Reefhuis J, Kucik J, et al. Case-control study of self reported genitourinary infections and risk of gastroschisis: findings from the national birth defects prevention study, 1997-2003. BMJ 2008;336:1420-3.

16. Elliott L, Loomis D, Lottritz L, et al. Case-control study of a gastroschisis cluster in Nevada. Arch Pediatr Adolesc Med 2009;163:1000-6.

17. Yazdy MM, Mitchell AA, Werler MM. Maternal genitourinary infections and the risk of gastroschisis. Am J Epidemiol 2014;180:518-25.

18. Baer RJ, Chambers CD, Jones KL, et al. Maternal factors associated with the occurrence of gastroschisis. Am J Med Genet $A$ 2015;167:1534-41.

19. Given JE, Loane M, Luteijn JM, et al. EUROmediCAT signal detection: an evaluation of selected congenital anomaly-medication associations. Br J Clin Pharmacol 2016;82:1094-109.

20. Ahrens KA, Anderka MT, Feldkamp ML, et al. Antiherpetic medication use and the risk of gastroschisis: findings from the national birth defects prevention study, 1997-2007. Paediatr Perinat Epidemiol 2013;27:340-5.

21. Feldkamp ML, Enioutina EY, Botto LD, et al. Chlamydia trachomatis IgG3 seropositivity is associated with gastroschisis. J Perinatol 2015;35:930-4.

22. Parker SE, Werler MM, Gissler M, et al. Maternal antibodies to chlamydia trachomatis and risk of gastroschisis. Birth Defects Res 2017;109:543-9.

23. Werler MM, Parker SE, Hedman K, et al. Maternal antibodies to herpes virus antigens and risk of gastroschisis in Offspring. Am J Epidemiol 2016;184:902-12.

24. Reefhuis J, Gilboa SM, Anderka M, et al. The National Birth Defects Prevention Study: A review of the methods. Birth Defects Res A Clin Mol Teratol 2015;103:656-69.

25. Rasmussen SA, Olney RS, Holmes LB, et al. the National birth defects prevention study. guidelines for case classification for the national birth defects prevention study. Birth Defects Res A Clin Mol Teratol 2003;67:193-201.

26. Cogswell ME, Bitsko $\mathrm{RH}$, Anderka M, et al. Control selection and participation in an ongoing, population-based, case-control study of birth defects: the national birth defects prevention study. Am J Epidemiol 2009;170:975-85.

27. Centers for Disease Control and Prevention. Sexually transmitted disease surveillance 2016. Atlanta: U.S: Department of Health and Human Services, 2017.

28. Andersson T, Alfredsson L, Källberg H, et al. Calculating measures of biological interaction. Eur J Epidemiol 2005;20:575-9.

29. Rothman K, Greenland S, Lash T. Modern epidemiology. 3rd edn. Philadelphia PA: Ippincott Williams \& Wilkins, 2008.

30. VanderWeele TJ, Knol MJ. A tutorial on interaction. Epidemio Method 2014;3:33-72.

31. Centers for Disease Control and Prevention. Sexually transmitted disease surveillance 2015. Atlanta: U.S: Department of Health and Human Services, 2016.

32. Casey PM, Long ME, Marnach ML. Abnormal cervical appearance: what to do, when to worry? Mayo Clin Proc 2011;86:147-51.

33. Geisler WM, Stamm WE. Genital Chlamydia Infections. In: Klausner JD, Hook EW, Current diagnosis and treatment of sexually transmitted diseases. New York: McGraw Hill Medical, 2007:75-83.

34. Nogueira AT, Braun KM, Carabeo RA. Characterization of the growth of chlamydia trachomatis in in vitro-generated stratified Epithelium. Front Cell Infect Microbiol 2017;7.

35. Muzny CA, Harbison HS, Austin EL, et al. Sexually transmitted infection risk among women is not fully explained by partner numbers. South Med J 2017;110:161-7.

36. Khan MR, Berger AT, Wells BE, et al. Longitudinal associations between adolescent alcohol use and adulthood sexual risk behavior and sexually transmitted infection in the United States: assessment of differences by race. Am J Public Health 2012;102:867-76.

37. Friis K, Østergaard J, Reese S, et al. Young people's attitudes towards illicit drugs: a population-based study. Scand J Public Health 2017;45:765-72. 
38. Dembo R, Belenko S, Childs K, et al. Drug use and sexually transmitted diseases among female and male arrested youths. $J$ Behav Med 2009;32:129-41.

39. Vincent CR, Thomas TL, Reyes L, et al. Symptoms and risk factors associated with first urinary tract infection in college age women: a prospective cohort study. J Urol 2013;189:904-10.

40. Bonny AE, Brouhard BH. Urinary tract infections among adolescents. Adolesc Med Clin 2005;16:149-61.

41. Swygard H, Sena AC, Leone P, et al. In: Klausner JD, Hook EW, Current diagnosis and treatment of sexually transmitted diseases. New York: McGraw Hill Medical, 2007:99-107.

42. Chart $\mathrm{H}$. Klebsiella, enterobacter, proteus and other enterobacteria. In: Greenwood D, Slack R, Peutherer J, Barer M. (eds). Medical microbiology. 17th edn. New York: Churchill Livingston Elsevier 2007:275-84

43. Chart H. Klebsiella, enterobacter, proteins, and other enterobacteria. In: Greenwood D, Slack R, Peutherer J, Barer M. (eds). Medical Microbiology. 17th edn. New York: Churchill Livingston Elsevier, 2007:285-92

44. Wilbanks MD, Galbraith JW, Geisler WM. Dysuria in the emergency department: missed diagnosis of Chlamydia trachomatis. West $J$ Emerg Med 2014;15:227-30.

45. Tomas ME, Getman D, Donskey CJ, et al. Overdiagnosis of urinary tract infection and underdiagnosis of sexually transmitted infection in adult women presenting to an emergency department. J Clin Microbiol 2015;53:2686-92.

46. Hafner LM, Wilson DP, Timms P. Development status and future prospects for a vaccine against Chlamydia trachomatis infection. Vaccine 2014;32:1563-71.

47. Stamm WE. Chlamydia trachomatis infections in the adult. In: Holmes KK, Sparling PF, Stamm WE, eds. Sexually transmitted disease. New York: McGraw Hill Medical, 2008:575-94.

48. Keat A, Thomas B, Dixey J, et al. Chlamydia trachomatis and reactive arthritis: the missing link. Lancet 1987;1:72-4.

49. Beutler AM, Whittum-Hudson JA, Nanagara R, et al. Intracellular location of inapparently infecting Chlamydia in synovial tissue from patients with Reiter's syndrome. Immunol Res 1994;13:163-71.

50. Kwiatkowska B, Filipowicz-Sosnowska A. Reactive arthritis. Pol Arch Med Wewn 2009;119:60-6.

51. Gérard HC, Carter JD, Hudson AP. Chlamydia trachomatis is present and metabolically active during the remitting phase in synovial tissues from patients with chronic Chlamydia-induced reactive arthritis. Am J Med Sci 2013;346:22-5.

52. Stewart J. Immunological principles: antigens and antigen recognition. In: Greenwood D, Slack R, Peutherer J, Barer M, eds. Medical Microbiology. 17th edn. New York: Churchill Livingston Elsevier, 2007:96-106.
53. Ward ME. Genital and ocular infections, infertility, atypical pneumonia. In: Greenwood D, Slack R, Peutherer J, Barer M. (eds) Medical Microbiology. 17th edition. New York: Churchill Livingston Elsevier, 2007:375-84.

54. Darville T, Hiltke TJ. Pathogenesis of genital tract disease due to Chlamydia trachomatis. J Infect Dis 2010;201:114-25.

55. Picard MD, Bodmer JL, Gierahn TM, et al. Resolution of chlamydia trachomatis infection is associated with a distinct $\mathrm{T}$ Cell response profile. Clin Vaccine Immunol 2015;22:1206-18.

56. Committee on AdolescenceSociety for Adolescent Health and Medicine. Screening for nonviral sexually transmitted infections in adolescents and young adults. Pediatrics 2014;134:e303-11.

57. Fanfair RN, Zaidi A, Taylor LD, et al. Trends in seroprevalence of herpes simplex virus type 2 among non-Hispanic blacks and nonHispanic whites aged 14 to 49 years-United States, 1988 to 2010. Sex Transm Dis 2013;40:860-4.

58. Markowitz LE, Liu G, Hariri S, et al. Prevalence of HPV After Introduction of the Vaccination Program in the United States. Pediatrics 2016;137:e20151968.

59. Alan Guttmacher Institute. Sex and America's teenagers. New York: Alan Guttmacher Institute, 1994.

60. Cates JR, Herndon NL, Schulz SL, et al. Our voices, our lives, our futures: Youth and sexually transmitted diseases. Chapel Hill, NC: University of North Carolina at Chapel Hill School of Journalism and Mass Communication, 2004.

61. Geisler WM, Morrison SG, Doemland ML, et al. Immunoglobulinspecific responses to Chlamydia elementary bodies in individuals with and at risk for genital chlamydial infection. $J$ Infect Dis 2012;206:1836-43.

62. Honein MA, Rasmussen SA, Reefhuis J, et al. Maternal smoking and environmental tobacco smoke exposure and the risk of orofacial clefts. Epidemiology 2007;18:226-33.

63. MacLehose RF, Olshan AF, Herring AH, et al. Bayesian methods for correcting misclassification: an example from birth defects epidemiology. Epidemiology 2009;20:27-35.

64. Srisukhumbowornchai S, Krikov S, Feldkamp ML. Self-reported maternal smoking during pregnancy by source in Utah, 2003-2007. Birth Defects Res A Clin Mol Teratol 2012;94:996-1003.

65. Russell A, Gillespie S, Satya S, et al. Assessing the accuracy of pregnant women in recalling pre-pregnancy weight and gestational weight gain. J Obstet Gynaecol Can 2013;35:802-9.

66. Ailes EC, Gilboa SM, Gill SK, et al. Association between antibiotic use among pregnant women with urinary tract infections in the first trimester and birth defects, national birth defects prevention study 1997 to 2011. Birth Defects Res A Clin Mol Teratol 2016;106:940-9. 